\title{
Implementasi Layanan Firebase pada Pengembangan Aplikasi Sewa Sarana Olahraga Berbasis Android
}

\author{
Teguh Kurniawan ${ }^{1}$, Samsudin $^{2}$, Triase $^{3}$ \\ ${ }^{1,2,3}$ Fakultas Sains dan Teknologi, UIN Sumatera Utara, Jln IAIN No.1 Medan, \\ Sumatera Utara, Indonesia, 20235 \\ e-mail: 'teguh.kurniawan@uinsu.ac.id, ${ }^{2}$ samsudin@uinsu.ac.id, ${ }^{3}$ triase@ uinsu.ac.id
}

Submitted Date: April $13^{\text {th }}, 2021$

Revised Date: June 02 $2^{\text {nd }}, 2021$
Reviewed Date: June 02 $2^{\text {nd }}, 2021$

Accepted Date: June $14^{\text {th }}, 2021$

\begin{abstract}
One of the business sectors that rarely gets digital innovation is the sports business sector, such as the sports field rental business. The problem in this business is that there are still many business actors and their customers who carry out the conventional reservation process, namely by making books manually and this has an impact on the customer experience when conducting leasing transactions, and for business actors it also has an impact on financial recapitulation due to incorrect calculations. The purpose of this research is to develop an Android-based application that is able to provide a much faster and easier sports rental transaction process by integrating with firebase services (firebase authentication, firebase realtime database, firebase cloud messaging). This study uses the method of developing the Rapid Application Development system and in collecting data using qualitative methods, namely observation, interviews, and literature study. From this research, an android-based application has been successfully developed that is able to solve the problem of conventional sports facilities rental and minimize the occurrence of calculation errors in financial recapitulation by integrating it with firebase services.
\end{abstract}

Keywords: Firebase service, Android, Sports Facility Rental

\begin{abstract}
Abstrak
Salah satu sektor bisnis yang jarang mendapatkan inovasi digital adalah sektor bisnis olahraga, seperti bisnis sewa sarana lapangan olahraga. Permasalahan pada bisnis ini masih banyak pelaku usaha dan pelanggan-nya yang melakukan proses reservasi secara konvensional yaitu dengan membuat pembukuan secara manual dan berdampak pada pengalaman pelanggan saat melakukan transaksi sewa menyewa, serta bagi pelaku usaha juga berdampak pada rekapitulasi keuangan akibat kesahalan perhitungan. Tujuan dari penelitian ini adalah mengembangkan aplikasi berbasis Android yang mampu memberikan proses transaksi sewa sarana olahraga jauh lebih cepat dan mudah dengan cara melakukan integrasi dengan layanan firebase (firebase authentication, firebase realtime database, firebase cloud messaging). Penelitian ini menggunakan metode pengembangan sistem Rapid Application Development dan dalam pengumpulan data, penelitian ini menggunakan metode kualitatif yaitu obeservasi, wawancara, dan studi pustaka. Dari penelitian ini telah berhasil di kembangkan sebuah aplikasi berbasis android yang mampu memecahkan masalah penyewaan sarana olahraga secara konvensional serta meminimalisir terjadinya kesalahan perhitungan pada rekapitulasi keuangan dengan melakukan integrasi kepada layanan firebase.
\end{abstract}

Kata Kunci: Layanan Firebase, Android, Sewa Sarana Olahraga

\section{Pendahuluan}

Sarana olahraga ialah sumber daya pendukung bagi manusia yang berbentuk dari segala jenis bangunan ataupun tidak dalam bentuk bangunan yang digunakan untuk keperluan kegiatan olahraga (Saputri, 2014), seperti lapangan olahraga dan fasilitas yang ada pada sarana olahraga tersebut. Sarana olahraga juga 
bisa dijadikan bisnis yaitu dengan menyewakan sarana olahraga tersebut kepada orang-orang yang membutuhkan.

Pada proses penyewaan sarana olahraga berserta fasilitasnya, calon penyewa harus langsung datang ke lokasi bersangkutan untuk menanyakan informasi berupa harga sewa per satu jam, ketersediaan jadwal (tanggal dan pukul berapa lapangan tersebut bisa digunakan), lalu pihak pengelola jasa sewa sarana olahraga tersebut akan melakukan pencatatan secara manual atas setiap transaksi yang terjadi guna dijadikan rekapitulasi keuangan nantinya.

Pada studi kasus ini sistem yang berjalan saat proses transaksi sewa menyewa masih dilakukan secara konvensional atau manual sehingga memunculkan masalah dianataranya, calon penyewa yang harus repot datang ke lokasi hanya untuk menanyakan informasi yang dibutuhkan seperti informasi harga dan jadwal tersedianya sarana olahraga tersebut, dan rekapitulasi keuangan akibat human error yang ditanggung pengelola sarana olahraga.

Pada penelitian ini menjelaskan aplikasi yang akan dikembangkan dengan memakai model pengembangan dengan Rapid Application Development (RAD) di mana tahapannya terdiri dari Requirements Planning, Design Workshop, Implementation (Rini \& Fatmariani, 2017).

Tujuan dan harapan dari penelitan ini adalah sebuah gagasan untuk mengembangkan sebuah wadah dalam bentuk aplikasi berbasis android bagi penyedia jasa sewa sarana olahraga dan pelanggan dalam melakukan transaksi sewa lapangan secara online, sehingga proses transaksi jauh lebih cepat dan rekapitulasi keuangan dari transaksi tersebut jauh lebih tepat karena dikalkulasi oleh komputer, dalam penerapan gagasan tersebut penelitian ini akan menggunakan layanan firebase agar tujuan yang dipaparkan di atas tercapai.

\section{Metodologi Penelitian}

Penelitian ini menggunakan pendekatan kualitatif dalam mengumpulkan data yang dilakukan dengan beberapa tahapan melalui observasi, wawancara, dan juga studi pustaka penelitian terdahulu yang berkaitan dengan studi kasus penelitian ini. Pengambilan sample dilakukan terhadap para penyedia jasa sewa sarana olahraga dan pelangganya di lima kecamatan di kota Medan yaitu Medan Estate, Medan Tembung, Medan Perjuangan, Medan Timur, dan Medan
Helvetia. Waktu penelitian ini dilakukan dari awal Januari 2020 hingga Maret 2020.

\section{Model Pengembangan Sistem}

Penelitian ini menggunakan model pengembangan sistem Rapid Application Development (RAD), di mana model ini adalah model pengembangan sistem yang mempunyai kelebihan karena tahapannya yang singkat dan juga cepat (Rini \& Fatmariani, 2017). Tahapan pada metode ini terdiri dari sebagai berikut (Aini \& Wicaksono, 2019):

\section{a. Requirements Planning}

Merupakan tahapan yang bertujuan untuk melakukan identifikasi kebutuhan di mana kebutuhan tersebut berupa informasi yang bisa dijadikan data-data yang berguna dalam pengembangan sistem nantinya.

\section{b. Design Workshop}

Merupakan tahapan yang bertujuan untuk melakukan analisa dan perancangan sistem dengan hasil output model dari sebuah sistem yang dikembangkan, pada penelitian ini model sistem dibuat dengan Unified Model Language.

\section{c. Implementation}

Merupakan tahapan di mana implementasi kode dilakukan yang mengikuti model sistem yang telah dirancang pada tahapan design workshop, hasil dari tahapan ini adalah sebuah aplikasi yang siap digunakan untuk memecahkan sebuah masalah yang bersangkutan.

\section{Layanan Firebase}

Layanan firebase merupakan sebuah teknologi dari perusahaan raksasa Google berbentuk platform yang tujuannya untuk memudahkan pengembangan sistem yang menggunakan sebuah resource REST API (Ilhami, 2017) dalam pengembangan aplikasi berbasis android untuk berkomukasi dengan server umumnya menggunakan REST API akan tetapi dalam proses pembuatannya sangatlah lama karena beberapa faktor seperti keamanan, kecepatan, dan kemudahan akses, firebase hadir untuk memangkas kegiatan pengembangan REST API tersebut sehingga memudahkan pengembang aplikasi dalam pembuatan aplikasi.

Adapun layanan firebase yang digunakan pada penelitian ini adalah sebagai berikut:

\section{a. Firebase Authentication}


Sebuah layanan dari firebase yang berfungsi untuk melakuka proses Authentication pada aplikasi, firebase authentication sendiri menyediakan cukup banyak metode autentikasi (pengenalan identitas user), pada saat penelitian ini dibuat adapun metode tersebut adalah email, phone number, facebook account, github account, google account, yahoo account, microsoft account, apple account, twitter account.

\section{b. Firebase Realtime Database}

Merupakan salah satu layanan dari firebase yang bertujuan untuk melakukan manajemen database, bersifat NoSQL dan dalam bentuk JSON. Layanan ini sangat optimal untuk digunakan karena kemampuannya dalam melakukan proses komunikasi dengan Client sangat cepat.

\section{c. Firebase Cloud Messaging}

Merupakan salah satu layanan firebase yang memungkinkan agar aplikasi saling berkirim pesan dan menerima pemberitahuan secara realtime. Penerapan layanan ini cocok digunakan untuk fitur chating dan handle notifikasi.

\section{Unified Model Language (UML)}

Merupakan standar bahasa dalam dokumentasi, melakukan spesifikasi, dan pembangunan dalam pengembangan sebuah software, yang mana menggunakan pendekatan Object Oriented Programming, beberapa diagram UML adalah sebagai berikut (Kurniawan, Syarif, Aulia, \& Pratama, 2019) :

\section{a. Use case}

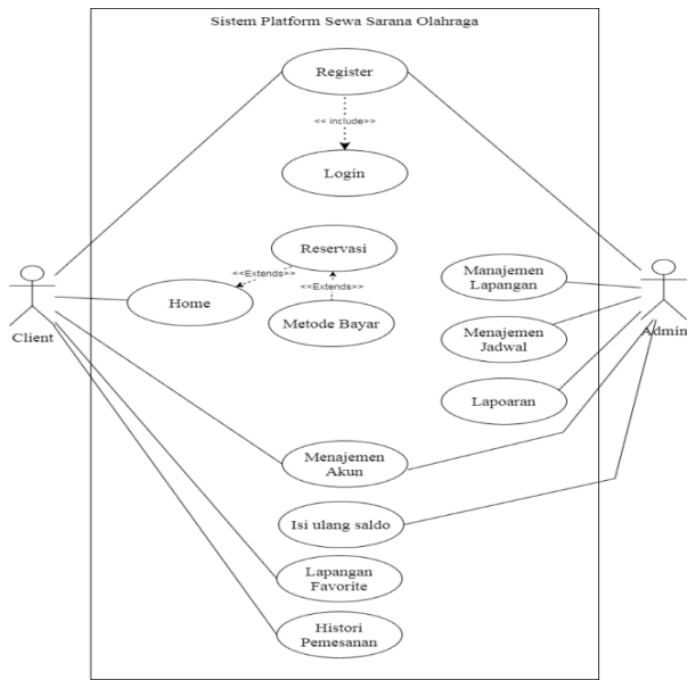

Merupakan diagram atau gambaran grafik dari beberapa aktor dan interaksi antar aktor yang mempresentasikan sebuah sistem dan memaparkan siapa aktor yang dapat mengerjakan prosedur pada sistem dan juga proses apa yang terkait pada sistem tersebut (Samsudin, 2019). Use case banyak digunakan oleh pengembang aplikasi dalam tahap pemodelan karena bisa dilihat secara umum hubungan antar aktor dan sistem bisa melakukan apa saja.

\section{b. Sequential Diagram}

Merupakan diagram langkah perubahan yang merujuk pada use case (Suendri, 2018). Bisa dikatakan juga sebagai serangkaian alir yang di lakukan pada sistem untuk menghasilkan output dari proses tertentu.

\section{Android}

Adalah sebuah sistem operasi mobile besutan Google yang berjalan diatas kernel linux dan bersifat Open Source. Struktur aplikasi android menggunakan bahasa pemrograman Java ataupun Kotlin, lalu dengan bahasa pemrograman tersebut di kompilasi sehingga menghasilkan sebuah file dengan ekstensi .apk yang mana file inilah yang bisa di pasang pada sistem operasi android (Dewi, Anandita, Atmaja, \& Aditama, 2018).

\section{Hasil dan Pembahasan}

Berikut adalah langkah penyelesaian pada penelitian ini mengikuti medel pengembangan sistem Rapid Application Development, yang dimulai dari tahapan requirements planning, design workshop, dan terakhir implementation.

\section{a. Tahap Requirements Planning}

Pada tahapan ini penelitian ini menhasilakan sebuah data yang didapatkan secara kualitatif dengan melakukan pendekatan observasi, wawancara, dan studi pustaka. Data yang dimaksud seperti data harga, siapa saja aktor yang terlibat untuk dijadikan user, data lokasi, data fasilitas, dan flow dari business logic proses sewa menyewa sarana olahraga tersebut.

b. Tahap Design Workshop

Pada tahapan ini membahas tentang desain model terhadap sistem yang akan dikembangkan sesuai kebutuhan menggunakan dua digaram Unified Model Language yaitu use case dan sequential diagram.

Gambar 1 Use Case Diagram Sistem 


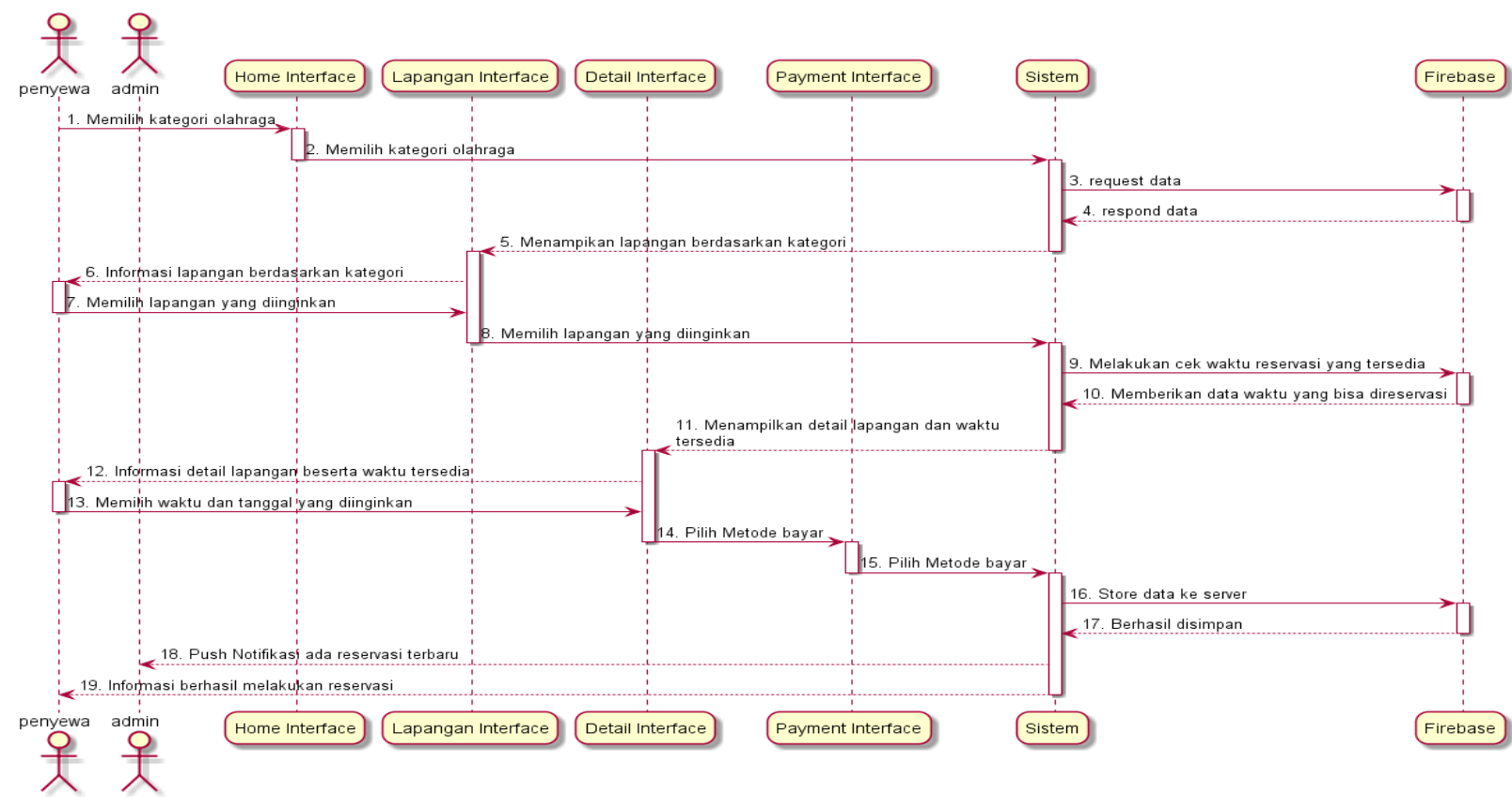

Gambar 2 Sequential Diagram Sistem

Pada gambar 1 adalah use case diagram di mana terdapat dua aktor, yaitu calon penyewa (client) dan pengelola lapangan (administrator), di mana masing-masing aktor dapat melakukan aksi seperti yang dipaparkan pada gambar, dan pada gambar 2 merupakan sequential diagram dari proses transaksi sewa sarana olahraga yang di lakukan secara online dan sudah di implementasikan dengan layanan firebase.

\section{c. Tahap Implementation}

Pada tahap ini menjelaskan bagaimana melakukan integrasi terhadap layanan firebase. Dalam penelitian ini hanya mengintegrasikan tiga layanan firebase yaitu firebase authentication, firebase realtime database, firebase cloud messaging di mana untuk melakukan proses integrasinya adalah sebagai berikut :

1. Mendaftakan Google Account ke layanan firebase di situs https://firebase.google.com/

2. Mendaftarkan aplikasi android (project) ke console firebase dengan SHA key android project.

3. Melakukan integrasi dengan SDK firebase melalui gradle.

Setelah melakukan tahap-tahap diatas aplikasi android sudah berhasil di integrasikan dengan layanan firebase (firebase authentication, firebase realtime database, dan firebase cloud messaging).
Berikut ini merupakan gambaran dari hasil implementasi firebase authentication pada aplikasi sewa sarana olahraga yang dikembangkan penelitian ini

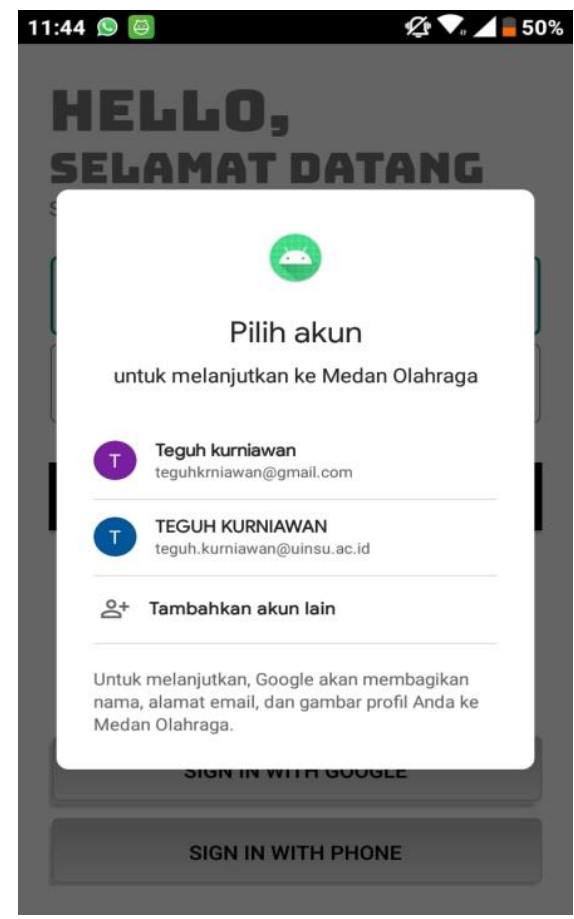

Gambar 3 Contoh penerapan firebase authentication 
Gambar di atas adalah penerapan firebase authentication menggunakan metode autentikasi google account, jadi ketika login sistem secara otomatis akan mendeteksi akun google untuk login.

\section{Authentication}

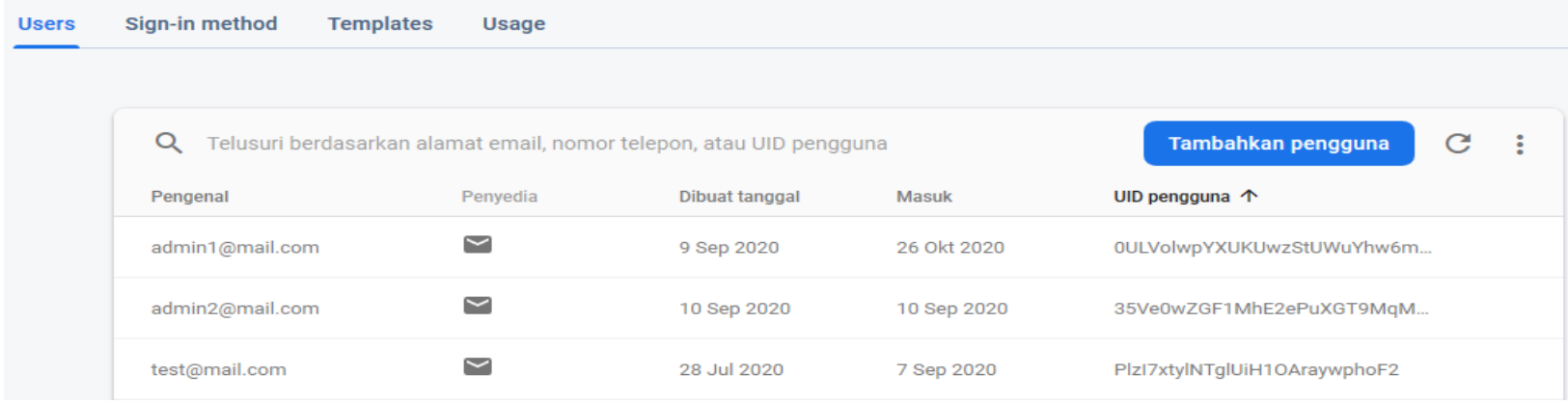

Gambar 4 Console dari firebase authentication

Berikut ini merupakan gambaran implementasi dari firebase realtime database pada aplikasi sewa sarana olahraga.

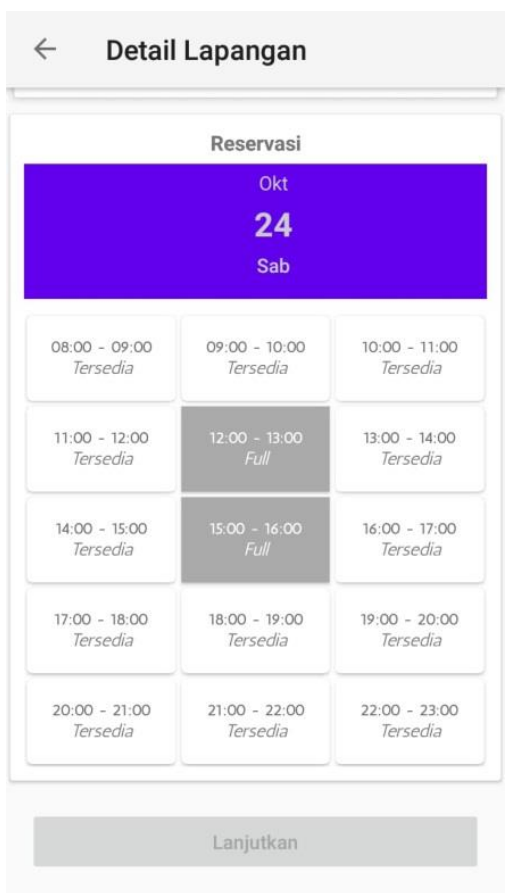

Gambar 5 Firebase Realtime Database Pada Sistem Untuk Menampilkan Informasi Jadwal Secara Real Time

Gambar 5 merupakan salah satu fitur yang dikembangkan pada aplikasi ini di mana calon penyewa dapat melihat secara real time tentang informasi jadwal ketersediaan lapangan pada hari yang di inginkan, dan fitur ini diterapkan menggunakan firebase realtime database. Adapun gambaran console dan bentuk struktur dari firebase realtime database tersebut ialah seperti pada gambar 6 .

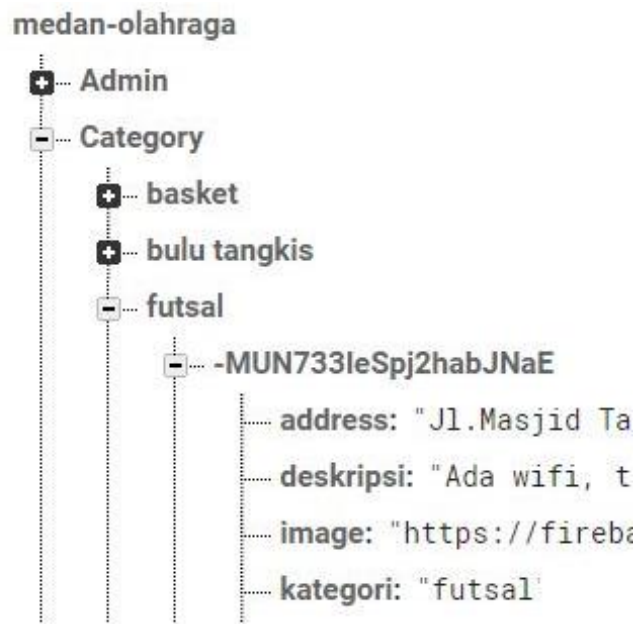

\section{Gambar 6 Contoh Struktur Data Firebase Realtime Database}

Berikut ini merupakan gambaran implementasi dari firebase cloud messaging pada aplikasi sewa sarana olahraga. 


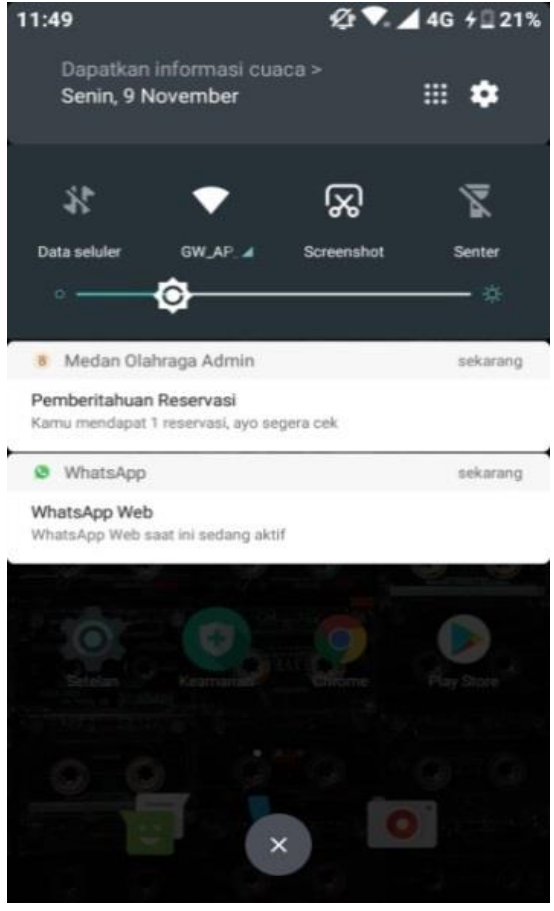

Gambar 7 Contoh Penerapan Firebase Cloud Messaging

Dalam penelitian ini implementasi firebase cloud messaging adalah untuk penerapan handle notifikasi, apabila calon penyewa melakukan proses reservasi tempat sarana olahraga, maka melalui layanan firebase cloud messaging ini akan mengirimkan sebuah response kepada pengelola lapangan yang ditampilkan lewat notifikasi, dan proses ini tentunya berjalan secara real time. Untuk dapat melakukan hit kelayanan firebase cloud messaging dapat dilakukan dengan menembakkan endpoint ke laman https://fcm.googleapis.com/fcm/send dari aplikasi android.

\section{Kesimpulan}

Dari penelitian yang telah dilakukan maka dapat ditarik kesimpulan sebagai berikut:

a. Layanan firebase benar-benar bisa memangkas proses pengembangan aplikasi khususnya pada sisi backend, karena sifatnya yang seperti tools.

b. Pengembangan aplikasi mampu membantu penyewa dalam melakukan proses transaksi yang lebih cepat dan mudah, dan membantu pengelola lapangan dalam membuat rekapitulasi keuangan yang akurat c. Firebase Authentication diterapkan untuk membantu proses autentikasi seperti login, firebase realtime database diterapkan untuk membantu penanganan data seperti penjadwalan dan rekapitulasi keuangan, dan firebase cloud messaging diterapkan untuk membantu penanganan notifikasi secara real time.

\section{Referensi}

Aini, N., \& Wicaksono, S. (2019). Pembangunan Sistem Informasi Perpustakaan Berbasis Web menggunakan Metode Rapid Application Development (RAD) (Studi pada: SMK Negeri 11 Malang). J-Ptiik.Ub.Ac.Id, 3(9), 9. Retrieved from http://j-ptiik.ub.ac.id/index.php/jptiik/article/download/6236/2996

Ceryna Dewi, N. K., Anandita, I. B. G., Atmaja, K. J., \& Aditama, P. W. (2018). Rancang Bangun Aplikasi Mobile Siska Berbasis Android. SINTECH (Science and Information Technology) Journal, 1(2), 100-107. https://doi.org/10.31598/sintechjournal.v2i1.291

Ilhami, M. (2017). Pengenalan Google Firebase Untuk Hybrid Mobile Apps Berbasis Cordova. Jurnal IT CIDA, 3(124), 16-29.

Kurniawan, T., Syarif, A., Aulia, R., \& Pratama, B. A. (2019). Perancangan dan Pengembangan EFinancial Transaksi Sewa Gedung Menggunakan Framework Laravel. Jurnal Informatika Universitas Pamulang, 4(4), 137. https://doi.org/10.32493/informatika.v4i4.3873

Rini, A., \& Fatmariani. (2017). Penerapan Metode RAD Pada Sistem Pengajuan Pengambilan Data Penelitian Bankesbangpol Kota Palembang. Jurnal TI Atma Luhur, 4(1), 1-12.

Samsudin. (2019). Optimalisasi Penerimaan Remunerasi Dosen Menggunakan Metode Rule Base Reasoning. Kumpulan JurnaL Ilmu Komputer (KLIK), 06(3), 224-240.

Saputri, V. V. I. (2014). Survei Sarana Dan Prasarana Olahraga Penunjang Proses Pembelajaran Penjasorkes Dan Pemanfaatannya Di Sekolah Luar Biasa Kabupaten Temanggung Tahun 2013. Journal of Physical Education, Sport, Health and Recreations, 3(11), 1402-1407. https://doi.org/10.15294/active.v3i11.4273

Suendri. (2018). Implementasi Diagram UML (Unified Modelling Language) Pada Perancangan Sistem Informasi Remunerasi Dosen Dengan Database Oracle (Studi Kasus: UIN Sumatera Utara Medan). Jurnal Ilmu Komputer Dan Informatika, $3(1), 1-9$. 